\title{
Trends in infectious disease incidence among children in Afghanistan at a time of public health services expansion
}

\author{
M.Y. Anwar ${ }^{7}$ and G. Burnham ${ }^{\prime}$
}

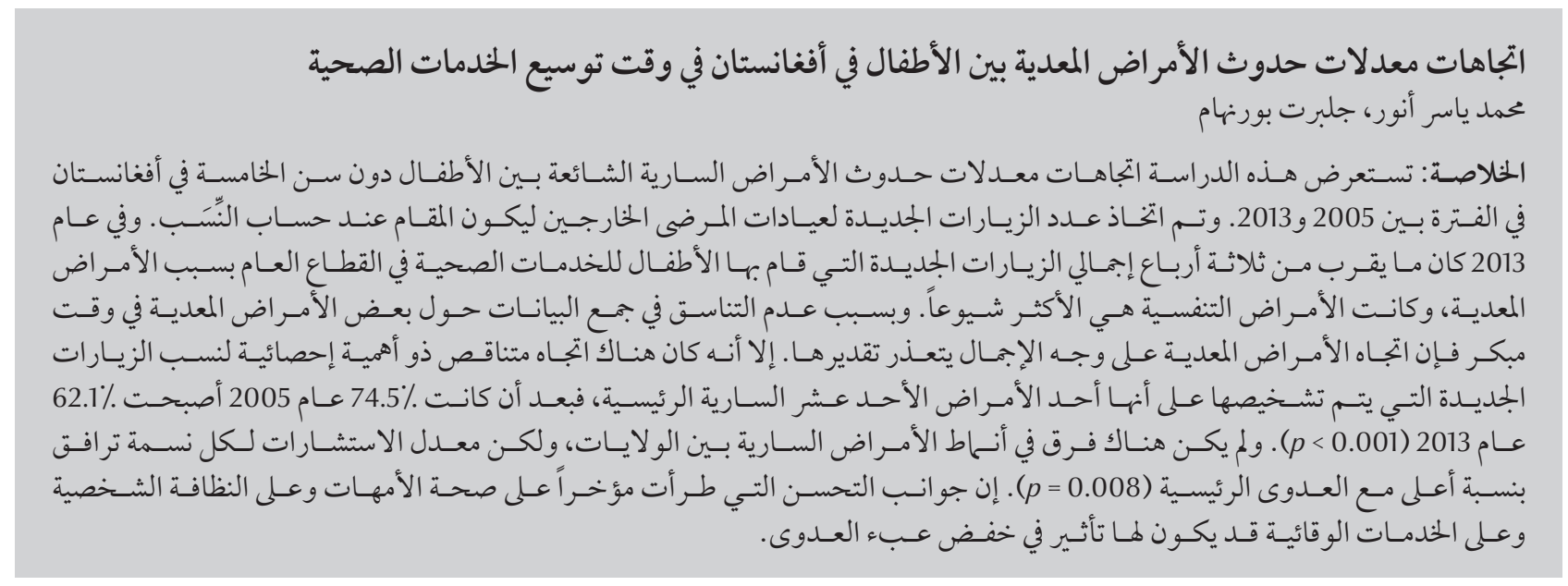

ABSTRACT This study reviewed trends in the incidence of common communicable diseases among children under five years in Afghanistan between 2005 and 2013, a period of expansion of public health services. New visits to outpatient clinics constituted the denominator for calculating proportions. In 2013, almost three-quarters of all new visits of children to public health services were for an infectious disease, with respiratory infections the most common. Because of inconsistent data collection for some infections early in the period, the trend for infectious diseases as a whole cannot be estimated. However, there was a statistically significant downward trend in the proportion of new visits that were diagnosed as one of the 11 leading communicable diseases from $74.5 \%$ in 2005 to $62.1 \%$ in $2013(P$ $<0.001)$. There was no difference in communicable disease patterns between provinces, but a higher per capita consultation rate was associated with a higher proportion of the leading infections $(P=0.008)$. Recent improvements in maternal health, hygiene, and preventive services may have had an impact in reducing the burden of infections.

Tendances de l'incidence des maladies infectieuses chez les enfants en Afghanistan à l'heure de I'élargissement des services de santé publique

RÉSUMÉ La présente étude a étudié les tendances de l'incidence des maladies transmissibles les plus répandues chez les enfants de moins de cinq ans en Afghanistan entre 2005 et 2013. Les premières consultations en soins ambulatoires ont constitué le dénominateur pour calculer les pourcentages. En 2013, près de trois quarts de toutes les premières consultations d'enfants dans les services de santé publique avaient pour cause une maladie infectieuse, les infections respiratoires étant les plus fréquentes. Du fait d'une collecte des données incohérente pour certaines infections au début de la période d'étude, les tendances pour les maladies infectieuses dans leur ensemble ne peuvent être estimées. Pour autant, une tendance à la baisse statistiquement significative a été observée en ce qui concerne le nombre de premières visites pour lesquelles le diagnostic établi était l'une des 11 maladies transmissibles les plus répandues (74,5 \% en 2005 contre 62,1\% en 2013, soit $p<0,0001$ ). Aucune différence en termes de caractéristiques des maladies transmissibles n'a été établie entre les provinces, mais un taux de consultation plus élevé par habitant a été associé avec un pourcentage plus élevé pour les infections principales $(p=0,008)$. Les récentes améliorations en matière de santé maternelle, $\mathrm{d}^{\prime}$ hygiène et de services de prévention ont pu avoir une influence sur la réduction de la charge des infections.

Johns Hopkins Bloomberg School of Public Health, Baltimore, MD, United States of America (Correspondence to: M.Y. Anwar: manwar6@jhu. edu).

Received: 28/08/15; accepted: 03/07/16 


\section{Introduction}

Afghanistan has suffered from instability and conflict for the past 40 years. Almost $36 \%$ of the population live below the poverty line (1) and access to public sector health facilities has historically been inadequate (2). In such a context, a high incidence of treatable diseases is to be expected. Children are particularly affected, not only because they are more vulnerable, but also because they constitute a large proportion of the Afghan population, of which $64 \%$ are under 24 years (2) and $17 \%$ under 5 years of age (3). The mortality rate for children under five years old is estimated to be 99 per 1000 live births, while the infant mortality rate is 71 per 1000 live births; with these rates, Afghanistan is 18th from last on the United Nations Children's Fund (UNICEF) ranking of countries for child health (3). Children's health is a sensitive reflection of the efficiency of the health services in a country.

In recent years, particularly since 2001, efforts have been made to expand public health services and increase access to them, as part of international cooperation to rebuild the country (4). Several studies have evaluated the association between these efforts and various health indicators, particularly in the areas of malnutrition, reproductive health, mortality and immunization, for both academic and planning purposes.

A less studied area is whether recent developments in Afghanistan have been associated with specific trends and characteristics of infectious diseases, particularly among children. While it is generally assumed that most diseases affecting children are communicable, precise numbers and trends have not been comprehensively studied, especially in relation to the recent expansion of public health services. A few sources, such as the Multiple Indicators Cluster Surveys (MICS) and the Afghanistan National Household Surveys, contain sections on infectious disease morbidity, but these are usually limited in scope. In the absence of systematic data, it is hard to calculate the prevalence of communicable diseases in the country.

The objective of this study was to assess trends in communicable diseases among children under five years of age, with particular attention to the most frequent infections, in light of recent efforts to invest in and expand public health services throughout the country. The results could provide some measure of the success of the efforts, as well as lessons for other similar undertakings.

\section{Methods}

The absence of a consistent health information system prior to 2004 makes the historical study of disease patterns among children difficult. Thus, we considered only reports on patterns, characteristics, and trends in communicable disease among children attending public health facilities from 2005 to 2013. During this period, public health facilities expanded considerably. We used data from facilities implementing the Basic Packages for Health Services (BPHS), which have been in place since 2002 (5). Nationally, nearly $80 \%$ of consultations for under-five-year-olds take place in these facilities (6). The number of such health facilities providing BPHS increased from 1075 in 2004 to over 2000 in 2014 (7).

In the absence of a national census, we used the totals for all "new visit" consultations for children in BPHS facilities as the denominator for calculating proportions; this method is also used in the Ministry of Public Health's Diseases Early Warning System (MoPHDEWS) (8). The data set is managed by the Health Management Information System (HMIS) Department of the Ministry, which defines a "new visit" as a visit at which "a patient [is] diagnosed with an episode of an illness for the first time". Return visits for the same diagnosis within a predefined period were considered as re-attendance, and were excluded from our analysis. The diagnoses categorized as communicable diseases among children under five years of age in HMIS are listed in Box 1;

\section{Box 1. Diseases categorized as communicable in HMIS records}

1. Cold and cough (ARI)

2. ENT (ear, nose, and throat) infection

3. Pneumonia (infectious)

4. Acute bloody diarrhoea

5. Acute watery diarrhoea

6. Diarrhoea with dehydration

7. Viral hepatitis

8. Measles

9. Pertussis

10. Diphtheria

11. Tetanus (neonatal)

12. Malaria

13. Urinary tract infection (UTI) (all types)

14. Gastrointestinal tract worms

15. Skin infections

16. Eye infections

17. Severely ill (infections with severe symptoms, not classified in other categories) 
classification is based on clinical manifestations.

We used data from 2013 to assess disease trends, seasonal fluctuations, and distribution by province. We then analysed trends in some key diseases between 2005 and the end of 2013 . Data analyses were performed with STATA statistical software (v.12) and Excel (v.2013). Linear regression analysis was used to evaluate the significance of associations. Reports from the World Health Organization, UNICEF, the United States Agency for International Development, and the Afghanistan $\mathrm{MoPH}$ were consulted for comparison.

\section{Results}

Monthly data returns for 2013 reported 13404322 new visits of children less than five years old to BPHS facilities for all conditions. Of these, 9678477 ( $72 \%)$ were diagnosed as having a communicable disease (Table 1). Among all first visits for communicable disease, respiratory infection was the most frequent diagnosis, with 2610013 cases of acute respiratory infection (ARI) (27\%) and 1067017 of pneumonia (11\%). Diarrhoea, ear, nose and throat infection, urinary tract infection, and malaria were the next most frequently reported infectious diseases.

There were no statistically significant seasonal fluctuations in the overall proportion of diagnoses of communicable diseases in 2013, although respiratory infections peaked around December-March (winter), diarrhoea in June-August (summer), and malaria in June-September. The totalnumber of first visits to outpatient departments of public health facilities by children under five years increased from 2883736 in 2005 to 13404322 in 2013 (Table 2), as a result of the expansion of the health infrastructure in Afghanistan during this period (7). From 2005 to 2010, there was an apparent downward trend in the proportion of first visits that were for communicable disease, which reversed after 2010 (Figure 1). This may reflect a change in the reporting forms in 2010 to include specific communicable diseases that had previously been recorded as "others", e.g. eye infections, intestinal worms, skin diseases, and oral-dental infections. This inconsistent recording of data means that no statistically significant trend can be distinguished in the proportion of new visits classified as communicable diseases, over the period 2005-13 (Table 2).

There was, however, a statistically significant downward trend in the proportion of new visits that were classified as one of the infections for which there was continuous reporting, in particular the 11 leading infections $(P$ $<0.001)$. Overall, the average decrease was around $1.8 \%$ per year (Table 3 ). Further breakdown of the data showed a reduction in the incidence of all these diseases, except ARI and measles (Table 3 and Figure 2). Malaria showed the most dramatic fall. Statistically similar patterns were seen in girls and boys.

Similar patterns of the leading infections were found in the different provinces, despite differences in climate and in socioeconomic and other characteristics. From 2008 to 2011 (9), higher consultation rates in provinces were positively correlated with higher proportions of visits for the leading communicable diseases (an average of 2.5\% increase for each point increase in per capita consultation rate $(P=0.008)$ ).

\section{Discussion}

Our results show that respiratory infections account for the biggest share of all new visits to public health facilities by children under five years. The finding is in line with previous studies $(8,10)$; of 247216 deaths reported among children under five in Afghanistan in 2008, 72716 (29.4\%) were attributed to pneumonia (11). Afghanistan is part of the list of those few countries that account for half of pneumonia-related deaths among children (11). However, despite continuing to be the most widespread disease among children, our analysis indicates a statistically significant reduction in the proportion of diagnoses of pneumonia between 2005

\begin{tabular}{lc}
\hline Table 1 Communicable diseases diagnosed in children aged under 5 years at health facilities in Afghanistan, 2013 \\
\hline Total number of new visits & 13404322 \\
No. of diagnoses of communicable disease (\% of all new visits) & $9678447(72.2 \%)$ \\
No. of diagnoses of specific infectious diseases (\% of all infectious diseases) & $2610013(27.0 \%)$ \\
ARI & $2581053(26.7 \%)$ \\
Diarrhoea & $1708129(17.6 \%)$ \\
ENT infection & $1067017(11.0 \%)$ \\
Pneumonia & $224727(2.3 \%)$ \\
Urinary tract infection & $43347(0.4 \%)$ \\
Malaria & $1444161(15.0 \%)$ \\
Other
\end{tabular}

$A R I=$ cold and cough 


\begin{tabular}{lcccc}
\hline \multicolumn{5}{l}{ Table 2 Diagnoses in children under 5 years attending health facilities in Afghanistan, 2005-2013 } \\
\hline Year & Communicable disease & Other conditions & Total new consultations & P value \\
2005 & $2168226(75.2 \%)$ & $715510(24.8 \%)$ & 2883736 & - \\
2006 & $313787(74.7 \%)$ & $1059956(25.3 \%)$ & 4197342 & - \\
2007 & $3737258(74.1 \%)$ & $1305145(25.9 \%)$ & 5042403 & - \\
2008 & $5077243(71.2 \%)$ & $2056401(28.8 \%)$ & 7133644 & - \\
2009 & $6041342(69.3 \%)$ & $2678126(30.7 \%)$ & 8719468 & - \\
2010 & $6629445(67.9 \%)$ & $3133727(32.1 \%)$ & 9763501 & - \\
2011 & $7900573(70.1 \%)$ & $3375465(29.9 \%)$ & 11276038 & - \\
2012 & $8675290(72.8 \%)$ & $3238986(27.2 \%)$ & 11914276 & - \\
2013 & $9678447(72.2 \%)$ & $3725875(27.8 \%)$ & 13404322 & N/A \\
Total & $53045540(71.4 \%)$ & $21289190(28.6 \%)$ & 74334730 & 0.157 \\
Boys & $27428378(71.8 \%)$ & $10748401(28.2 \%)$ & 38175279 & - \\
Girls & $25617162(70.8 \%)$ & $10540789(29.2 \%)$ & 36156416 & \\
\hline
\end{tabular}

P value is for annual trend.

and 2013. There may be several possible explanations for why incidence rates are falling while mortality remain high for respiratory infections. It may be that many cases are not reported to the database that we used, but are accounted for through other means (remembering that there are considerable areas where there are still no regular services). Or it could be that, in the information system, children who die from pneumonia are categorized as severely ill patients, using the Integrated Management of Childhood Illnesses (IMCI) classification, and may be reported separately on an IMCI form (12). Therefore, while there may have been a modest reduction in pneumonia, as found also in another recent study (8), the apparent dramatic decrease in morbidity rates found here should be viewed with great caution.

In general, the findings indicate that almost three-quarters of all new visits of children to public health facilities are for communicable diseases. Reports from DEWS indicate that the proportion of communicable disease diagnoses in all outpatient departments in public sector facilities for all age groups is between $60 \%$ and $80 \%$ (8). This suggests that, whatever the trends, the burden of communicable diseases in Afghanistan is still very great.

Although no association was found between geographical location and burden of infections among children, we found that the higher the per capita consultation rate, the higher the proportion of diagnoses for the leading 11 communicable diseases among children. It is likely that, in rural provinces, consultation rates in the public sector facilities are higher, as there is a paucity of private clinics in these areas. It may also be that larger family sizes in rural areas create a higher demand for paediatric care. A report in 2014 found a higher risk of death from infectious causes among children in remote rural areas, consistent with our analysis (13). It is interesting that no difference was observed in the proportion of infections among boys and girls, contrary to popular perception that boys are more vulnerable.

The incidence of the leading infectious diseases appears to be declining. Similarly, the DEWS reported a reduction in communicable diseases among the general population from 2007 to 2013 , comparing their annual reports in

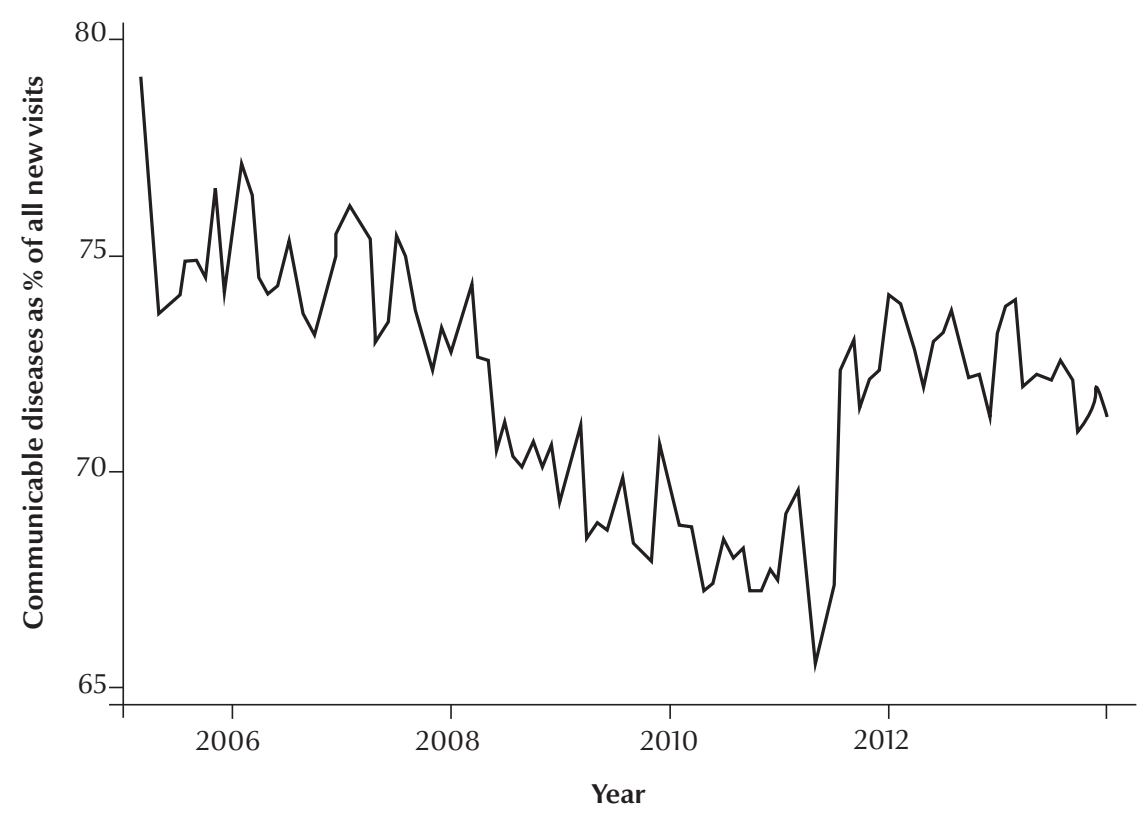

Figure 1. Communicable disease diagnoses among children under 5 years, as percentage of all new visits, reported from health facilities (monthly reports), January 2005 to December 2013 


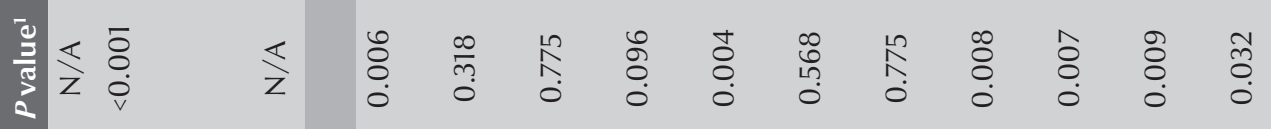

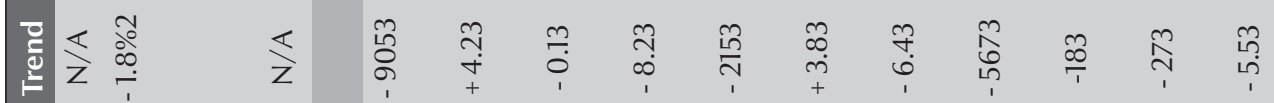

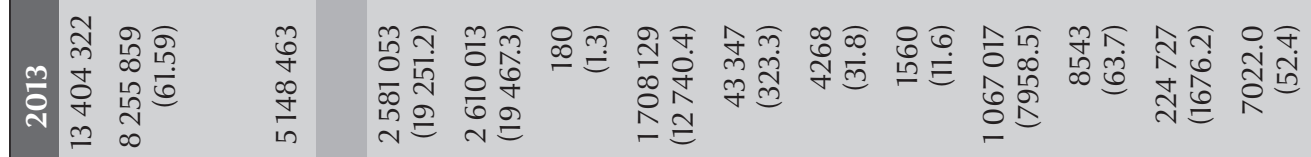

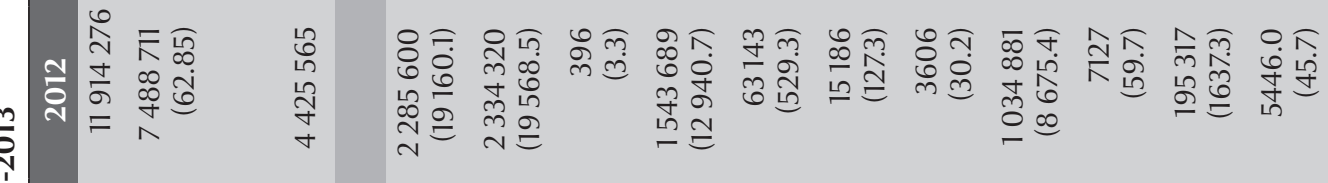

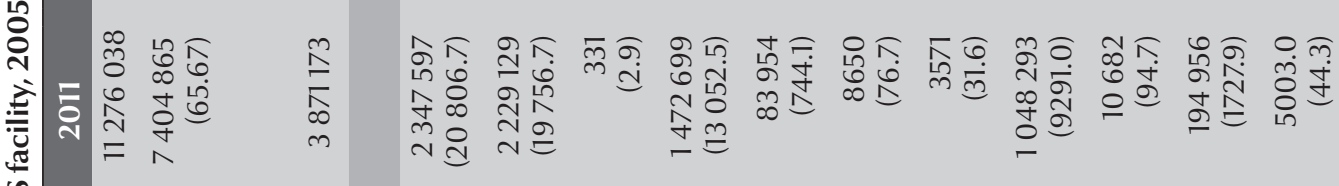

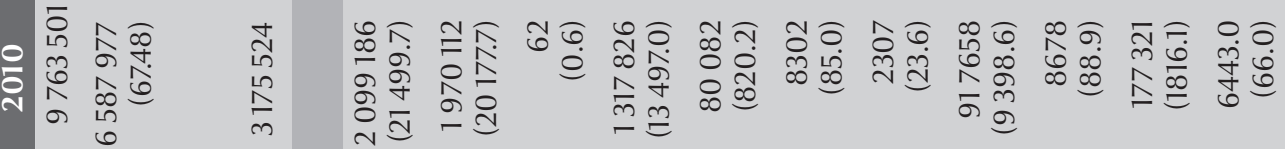

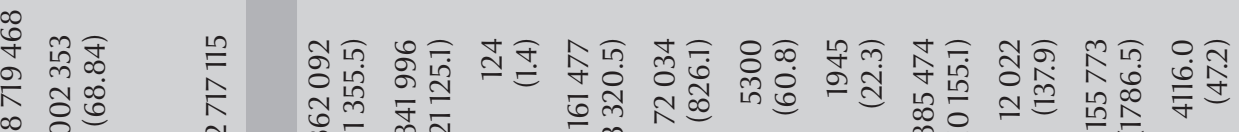

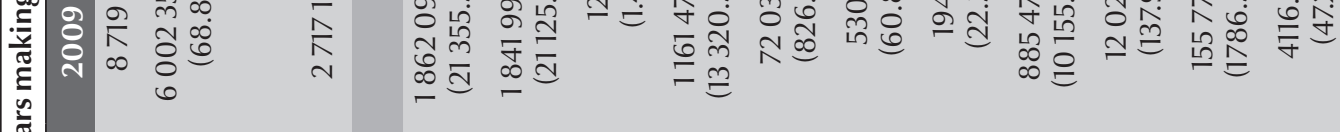

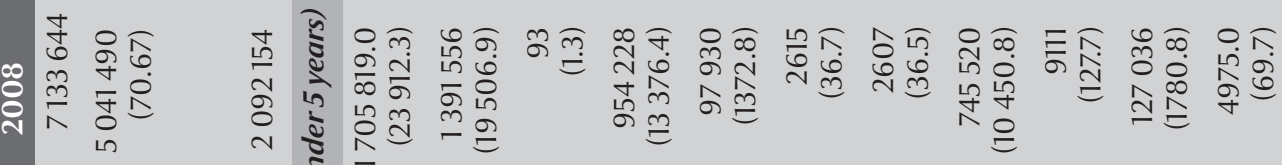
단.

2

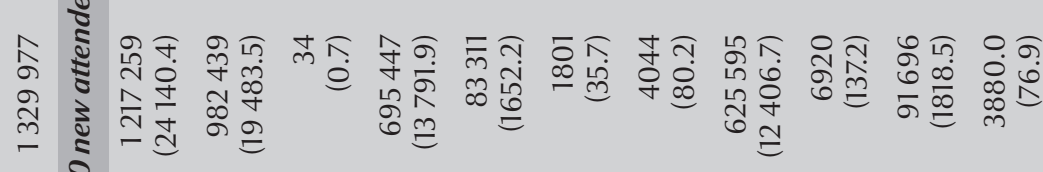

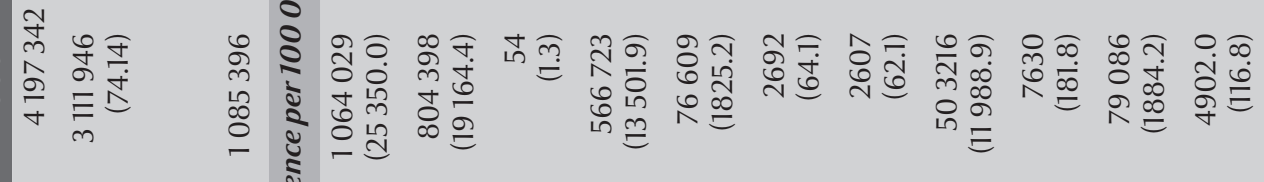

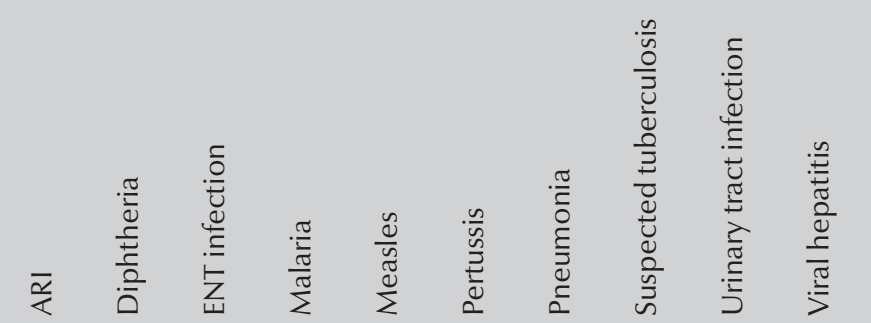



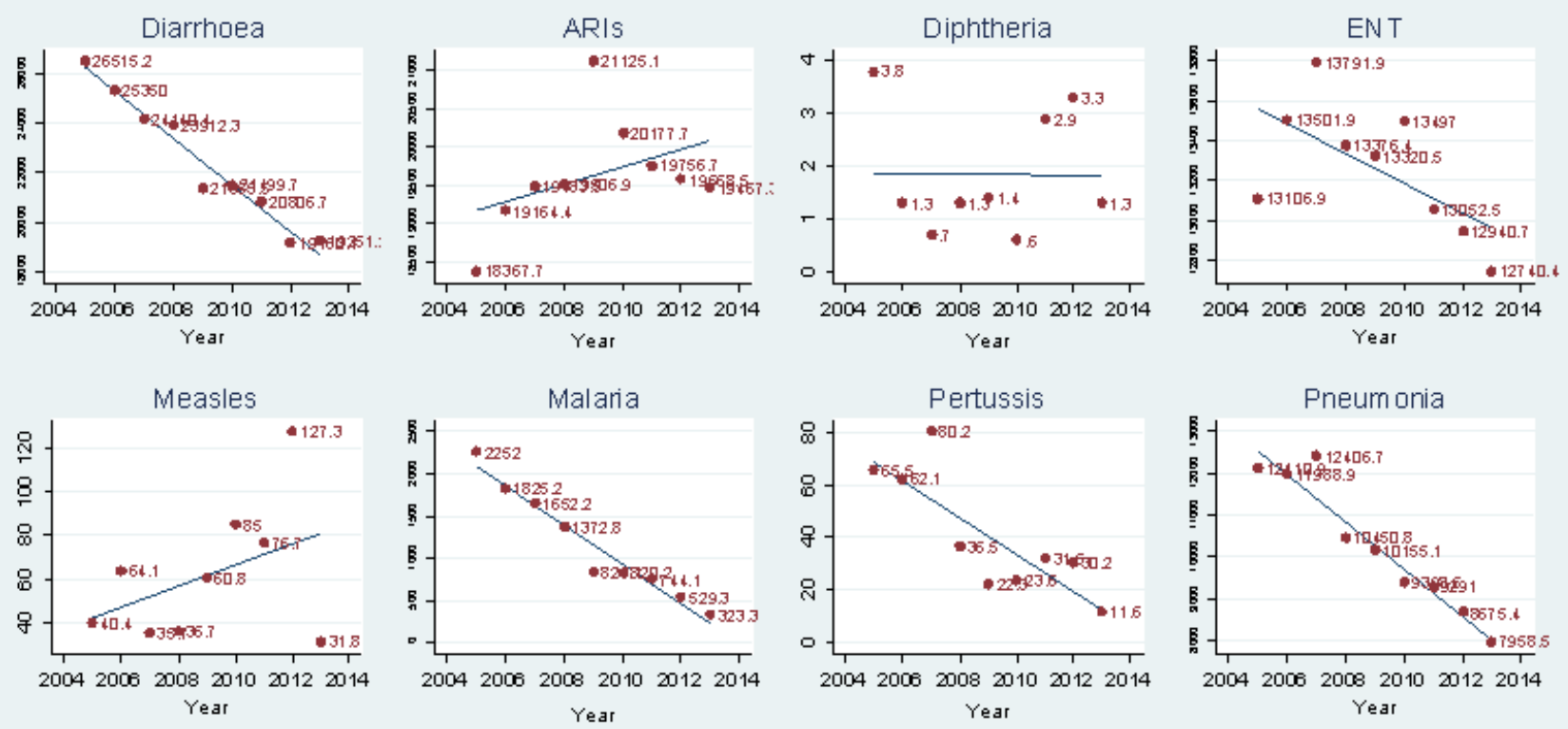

Suspected tuberculosis

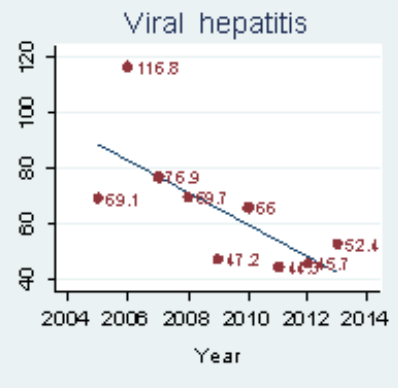

Urinary tract infections
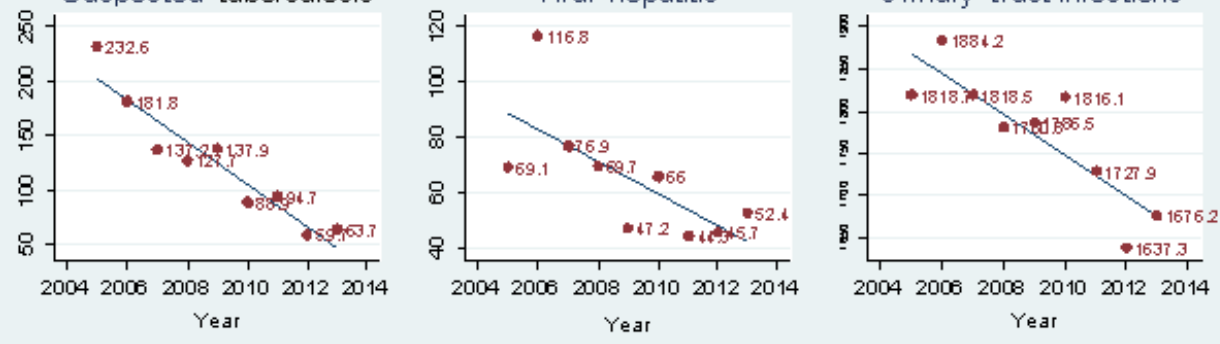

Figure 2. Trends in diagnoses of 11 leading infections (incidence per 100000 new visits) among children under 5 years attending health facilities, 2005-2013

this period based on assessment of a wider datasets. Another study reported that the proportion of disability-adjusted life years (DALYs) attributable to communicable and neonatal diseases was $48.9 \%$ in 2010 , a reduction of $20 \%$ from 1990 (14). Thus, as suggested by these other sources, there may be a real downward trend in some important childhood infections, if not in all.

It is plausible that efforts to improve the public sector health services in Afghanistan since 2002 have contributed to the reduction in pneumonia and other communicable diseases in the country (15). These investments, aimed at improving service delivery, especially for women and children (16), have produced results that may be associated with reduced childhood morbidity, including: a reduction of almost threequarters in the maternal mortality rate (17), which is attributed to better antenatal and postnatal care (18); an increase of $4000 \%$ in the number of births attended by a skilled birth attendant (7); and improved family planning services (19). Another relevant development may be the improvements in water supply, sanitation and hygiene.

The MICS survey in 2010-11 found that $57 \%$ of the population had access to clean water and hygiene, a substantial improvement compared with the early 2000s (20). According to field studies, better access to clean water is the reason for the reduced incidence of diarrhoea and typhoid (8). A study in Wardak province demonstrated that a water and hygiene intervention resulted in a $40 \%$ reduction in diarrhoea-related illness (21). Improved water and sanitation may also be associated with the reduction in outbreaks of viral hepatitis, which is mostly transmitted through contaminated food and water (22). Other contributory factors could be the wider implementation of preventive measures and control programmes, such as vaccination campaigns and distribution of insecticide-treated nets (ITNs), which are credited with reducing the incidence of poliomyelitis and malaria, respectively (8). In some parts of Afghanistan, up to $75 \%$ of the population uses ITNs (23).

We found some reports of circumstances that could potentially or actually hinder efforts to reduce the burden of childhood infections. These include 
inadequate vaccine coverage. In the case of measles, the coverage was reported by different sources to be as low as $44 \%$ in the second quarter of 2012 (24), $62 \%$ in 2011 (3) and 56.7\% in 2010/11 (20). Continued insecurity and a low level of education among women, particularly in rural areas (8), may have hampered vaccination efforts. Such low coverage in a context of high birth rates can only mean frequent outbreaks, which may also have distorted the trends in measles and poliomyelitis in our analysis. The high rate of malnutrition among children (25), a consequence of food insecurity (26), poor economy, extreme weather conditions, and ongoing conflict, may further contribute to mortality rates. The interaction between malnutrition and childhood infections (27), which results in a vicious cycle of more infections, makes it harder to tackle the burden of infections. While the fertility rate in Afghanistan is falling, the birth rate is still high compared with other countries in the region, at 39-48 per 1000 population (28). With high fertility rates, it is harder to reduce the burden of some infections, e.g. measles, as has been observed in other regions of the world (29). Furthermore, a shortage of qualified health professionals adds to the challenge (2).

\section{Limitations of results}

Our main source of information for this study was reports to the HMIS, which started collecting data in 2003. The data are not collected under the rigorous conditions typically applied to designed studies. The majority of cases are diagnosed and reported on the basis of clinical manifestations; thus, incorrect classification, resulting in over- or under-reporting, is an occasional problem (30).

Another limiting factor is the difficulty of establishing reference points and denominators for morbidity rates, because of the lack of national census data. For this reason, we chose to use proportions rather than rates, and children attending outpatient departments as the denominator, rather than those in the general population. This might not reflect health service use by some parts of the population, e.g. those who prefer to use the private sector, which is not regulated and does not contribute data to the national system (31). It is possible that higher-earning groups have lower incidence rates of disease.

\section{Conclusion}

While children are still affected by a high burden of infectious diseases, the picture is gradually improving for at least a few key communicable diseases. Although it is hard to attribute the observed results to specific factors, recent progress in maternal health, access to clean water and hygiene, and wider implementation of control programmes - all as a result of recent public health programmes - may have been associated with the reduction in infectious diseases among children. However, if the momentum is to be sustained, policy-makers and health planners need to address remaining challenges, through continued investment in quality health services and infrastructure, especially in areas such as vaccine coverage, food security, awareness of hygiene and nutrition, training of health personnel, and programme monitoring.

\section{Acknowledgements}

We thank the Ministry of Public Health of Afghanistan for allowing us access to their database; particular thanks go to Dr Sayed Yaqoob Azimi, Head of the HMIS Department, and to Dr Wudod Safi, Consultant to the HMIS Department.

\section{Funding: None.}

Competing interests: None declared.

\section{References}

1. Country profile. Afghanistan. Washington, DC: World Bank; 2013 (http://data.worldbank.org/country/afghanistan, accessed 13 May 2014).

2. Blood PR. Afghanistan: a country study. Health. Washington, DC: Government Publishing Office for the Library of Congress; 2001 (http://countrystudies.us/afghanistan/79.htm, accessed 1 April 2014).

3. Afghanistan. Statistics. New York: United Nations Children Fund; 2013 (http://www.unicef.org/infobycountry/afghanistan_statistics.html, accessed 30 Dec 2014).

4. Strong L, Wali A, Sondorp E. Health policy in Afghanistan: two years of rapid change. London: London School of Hygiene \& Tropical Medicine; 2005: 8-9.

5. Ministry of Public Health. A basic package of health services for Afghanistan. Kabul; 2003 (http://unpan1.un.org/intradoc/ groups/public/documents/apcity/unpan018852.pdf, accessed 12 October 2016).
6. Mubarak MS, Newbrander W. Basic package of health services - foundation of Afghanistan's health system. Arlington (VA): USAID BASICS; 2009 (http://www.basics.org/reports/ BPHS_Foundation_of_the_Health_System.pdf, accessed 15 May 2014).

7. Newbrander W, Ickx P, Feroz F, Stanekzai H. Afghanistan's basic package of health services: its development and effects on rebuilding the health system. Glob Public Health. 2014;9 (Suppl. 1):S6-28. PMID:24865404

8. Ikram MS, Powell CL, Bano RA, Quddus AD, Shah SK, Ogden EL et al. Communicable disease control in Afghanistan. Glob Public Health. 2014;9 (Suppl. 1):S43-57. PMID:24028403

9. HMIS Department. Afghanistan provincial health profile. Kabul: Ministry of Public Health; 2013.

10. Reilley B, Frank T, Prochnow T, Puertas G, Van Der Meer J. Provision of health care in rural Afghanistan: needs and challenges. Am J Public Health. 2004; 94(10):1686-8. PMID:15451732 
11. Black RE, Cousens S, Johnson HL, Lawn JE, Rudan I, Bassani DG et al.; Child Health Epidemiology Reference Group of WHO and UNICEF. Global, regional, and national causes of child mortality in 2008: a systematic analysis. Lancet. 2010;375(9730):1969-87. PMID:20466419

12. Treat the child. Geneva: World Health Organization, United Nations Children's Fund; 2009 (http://www.basics.org/documents/IMCI-Short-Course_Module-03_Treat_Afghanistan. pdf, accessed 10 May 2014).

13. Adegboye OA, Kotze D. Causes and patterns of morbidity and mortality in Afghanistan: Joint estimation of multiple causes in the neonatal period." Canadian Studies in Population. 2014;41(1-2):165-179.

14. Shahraz S, Forouzanfar MH, Sepanlou SG, Dicker D, Naghavi P, Pourmalek F et al. Population health and burden of disease profile of Iran among 20 countries in the region: from Afghanistan to Qatar and Lebanon. Arch Iran Med. 2014;17(5):336-42. PMID:24784862

15. Richards T. Access to health care in Afghanistan is improving, study shows. BMJ. 2007;334(7600):925. PMID:17478827

16. Edward A, Dwivedi V, Mustafa L, Hansen PM, Peters DH, Burnham G. Trends in the quality of health care for children aged less than 5 years in Afghanistan, 2004-2006. Bull World Health Organ. 2009;87(12):940-9. PMID:20454485

17. Adams K. Afghanistan: a healthy future? BMJ. 2014;348:g3950 PMID:24927765

18. Rasooly $\mathrm{MH}$, Govindasamy P, Aqil A, Rutstein S, Arnold F, Noormal B et al. Success in reducing maternal and child mortality in Afghanistan. Glob Public Health. 2014;9 (Suppl. 1):S29-42. PMID:24003828

19. Sato M. Challenges and successes in family planning in Afghanistan. Medford: Management Sciences for Health; 2007 (Occasional Papers 6).

20. Afghanistan Multiple Indicator Cluster Survey 2010-2011. New York: United Nations Children Fund; 2011 (http://www.childinfo.org/files/Afghanistan_2001-11_MICS_Final_Report.pdf, accessed 10 May 2014).
21. Opryszko MC, Majeed SW, Hansen PM, Myers JA, Baba D, Thompson RE et al. Water and hygiene interventions to reduce diarrhoea in rural Afghanistan: a randomized controlled study. J Water Health. 2010;8(4):687-702. PMID:20705980

22. Ashbolt NJ. Microbial contamination of drinking water and disease outcomes in developing regions. Toxicology. 2004;198(13):229-38. PMID:15138046

23. Leslie T, Mohammed N, Omar H, Rasheed HU, Vorst F, Sediqi AM. Malaria sentinel surveillance in Afghanistan. Afghanistan Annual Malaria Journal. 2008; 114-28.

24. GD of policy and planning. Kabul: Ministry of Public Health; 2012 (http://moph.gov.af/Content/Media/Documents/ HMISNEWSLETTERJUNE201219201293557514553325325.pdf) accessed 12 June 2014).

25. Vogel L. Afghan people risk their lives to obtain health care: MSF. CMAJ. 2014;186(6):411. PMID:24616140

26. Afghanistan. Rome: World Food Programme; 2014 (http:// www.wfp.org/countries/afghanistan/food-security, accessed 12 June 2014).

27. Schlaudecker EP, Steinhoff MC, Moore SR. Interactions of diarrhea, pneumonia, and malnutrition in childhood: recent evidence from developing countries. Curr Opin Infect Dis. 2011;24(5):496-502. PMID:21734569

28. World health statistics 2010. Geneva: World Health Organization; 2010.

29. Ferrari MJ, Grais RF, Bharti N, Conlan AJ, Bjørnstad ON, Wolfson LJ et al. The dynamics of measles in sub-Saharan Africa. Nature. 2008;451(7179):679-84. PMID:18256664

30. Saeed KMI, Bano R, Asghar RJ. Evaluation of national tuberculosis surveillance system in Afghanistan. Eastern Mediterranean Health Journal. 2013;19(2): 200-207.

31. Afghanistan private sector health survey. Washington, DC: United States Agency for International Development; 2009 (http://pdf.usaid.gov/pdf_docs/PNADQ185.pdf, accessed 13 May 2014). 